\title{
Monitoring of active layer dynamics at a permafrost site on Svalbard using multi-channel ground-penetrating radar
}

\author{
S. Westermann ${ }^{1}$, U. Wollschläger ${ }^{2, *}$, and J. Boike ${ }^{1}$ \\ ${ }^{1}$ Alfred-Wegener-Institute for Polar and Marine Research, Telegrafenberg A43, 14473 Potsdam, Germany \\ ${ }^{2}$ Institute of Environmental Physics, Ruprecht-Karls-University Heidelberg, 69120 Heidelberg, Germany \\ * now at: UFZ - Helmholtz Centre for Environmental Research, Permoserstraße 15, 04318 Leipzig, Germany
}

Received: 11 March 2010 - Published in The Cryosphere Discuss.: 22 March 2010

Revised: 28 October 2010 - Accepted: 29 October 2010 - Published: 8 November 2010

\begin{abstract}
Multi-channel ground-penetrating radar is used to investigate the late-summer evolution of the thaw depth and the average soil water content of the thawed active layer at a high-arctic continuous permafrost site on Svalbard, Norway. Between mid of August and mid of September 2008, five surveys have been conducted in gravelly soil over transect lengths of 130 and $175 \mathrm{~m}$ each. The maximum thaw depths range from $1.6 \mathrm{~m}$ to $2.0 \mathrm{~m}$, so that they are among the deepest thaw depths recorded in sediments on Svalbard so far. The thaw depths increase by approximately $0.2 \mathrm{~m}$ between mid of August and beginning of September and subsequently remain constant until mid of September. The thaw rates are approximately constant over the entire length of the transects within the measurement accuracy of about 5 to $10 \mathrm{~cm}$. The average volumetric soil water content of the thawed soil varies between 0.18 and 0.27 along the investigated transects. While the measurements do not show significant changes in soil water content over the first four weeks of the study, strong precipitation causes an increase in average soil water content of up to 0.04 during the last week. These values are in good agreement with evapotranspiration and precipitation rates measured in the vicinity of the the study site. While we cannot provide conclusive reasons for the detected spatial variability of the thaw depth at the study site, our measurements show that thaw depth and average soil water content are not directly correlated.
\end{abstract}

The study demonstrates the potential of multi-channel ground-penetrating radar for mapping thaw depth in per-

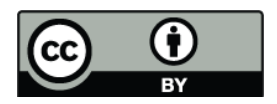

Correspondence to: S. Westermann (sebastian.westermann@awi.de) mafrost areas. The novel non-invasive technique is particularly useful when the thaw depth exceeds $1.5 \mathrm{~m}$, so that it is hardly accessible by manual probing. In addition, multichannel ground-penetrating radar holds potential for mapping the latent heat content of the active layer and for estimating weekly to monthly averages of the ground heat flux during the thaw period.

\section{Introduction}

About $24 \%$ of the land area of the Northern Hemisphere is underlain by permafrost, of which most occurs in arctic regions (Brown et al., 1997). These regions are anticipated to be severely affected by climate change (e.g. Overland et al., 2008), and a considerable reduction of the permafrost area is projected until 2100 (e.g. Delisle, 2007; Lawrence et al., 2008). The warming will have strong impacts on the ecology (e.g. Jorgenson et al., 2001), infrastructure (Parker, 2001) and economy (Prowse et al., 2009) of the arctic permafrost regions. A sustained warming trend in the Arctic over the past decades has been revealed by a number of studies (e.g. Serreze et al., 2000; Comiso and Parkinson, 2004), which is also reflected in widely increasing permafrost temperatures (e.g. Hinzman et al., 2005; Osterkamp, 2005).

The degradation of permafrost usually is preceded by an increase in the thickness of the active layer, followed by the formation of a talik and the subsequent thawing of the remaining permafrost body from top and bottom. An ongoing monitoring of the active layer thickness might therefore serve as an "early-warning system" to detect the onset of permafrost degradation. Recent studies suggest an increase

Published by Copernicus Publications on behalf of the European Geosciences Union. 
of the thaw depth in permafrost areas (Oelke et al., 2004; Zhang et al., 2005), while others do not detect an increase in thaw depth despite of a warming of the permafrost temperatures (Osterkamp, 2007). On Svalbard, considerable interannual variations of the active layer thickness are common (Christiansen and Humlum, 2008; Christiansen et al., 2010) which might obscure long-term trends. In the Kap Linné area, Åkerman (2005) reports an increase of the active layer thickness since the 1980s in conjunction with increasing air temperatures. Isaksen et al. (2007) report increasing permafrost temperatures in a borehole in Nordenskiöldland during the last decade, which is accompanied by a moderate increase in active layer thickness by 10 to $30 \mathrm{~cm}$.

The active layer, defined as "the top layer of ground subject to annual thawing and freezing in areas underlain by permafrost" (Harris et al., 1988), is the biologically active zone of the soil, where formation and decomposition of organic material can occur. Zimov et al. (2006) suggest that degradation of permafrost and an increase in active layer thickness will make large amounts of previously frozen organic material available for decomposition, which may lead to a massive release of methane and carbon dioxide from permafrost regions. The activation of this carbon stock would convert northern permafrost regions from net sinks to net sources of greenhouse gases (Schuur et al., 2008), resulting in an amplification of the global warming trend. To develop realistic predictions for this scenario, it is imperative to map and monitor the dynamics of the active layer and understand the controlling factors for the seasonal thawing.

In the framework of the "Global Terrestrial NetworkPermafrost" (GTN-P), the "Circumpolar Active Layer Monitoring" program (CALM) has provided measurements of the active layer thickness at more than 150 sites (Nelson et al., 2008). At some sites, repeated measurements are performed to resolve the seasonal evolution of the thaw depth (e.g. Shiklomanov et al., 2008). These measurements are traditionally conducted manually using a frost probe (Brown et al., 2000). On an area of $100 \times 100 \mathrm{~m}^{2}$ or larger, many single probings are performed to account for a potential spatial variability of the thaw depth and to limit the impact of single erroneous probings due to stones or other impenetrable structures in the ground. The method is satisfactory in soft soils, where the thaw depth does not greatly exceed one meter. In rocky soils or in case of much greater thaw depths, manual methods become increasingly difficult: the frost probe cannot penetrate easily to the frost table, so that it becomes hard to verify that it has been reached (Hinkel and Nelson, 2003). As a future increase in active layer thickness is likely for many of the existing CALM sites, it is desirable to develop and validate alternative methods for the monitoring of the active layer thickness.

Ground-penetrating radar (GPR) is a non-invasive geophysical technique, which has been used in a number of studies for mapping the depth of the frost table in permafrost regions (Annan and Davis, 1976; Arcone et al., 1998; Hinkel et al., 2001; Moorman et al., 2003; Schwamborn et al., 2008). Bradford et al. (2005) and Brosten et al. (2006) use GPR to monitor the seasonal dynamics of the thaw bulb beneath small streams in permafrost regions. In the framework of the CALM program, the use of GPR for mapping thaw depth has been proposed by Brown et al. (2000), but the technique has not become established yet. GPR is well suited for investigating thaw depth, as the abrupt increase of the dielectric permittivity at the interface between thawed and frozen soil induces a strong reflection of the electromagnetic signal. However, lateral variations of the soil water content cause a non-constant velocity of the GPR signal (e.g. Davis and Annan, 1989), which can lead to a considerable bias in the reflector depth, if the signal velocity is only calibrated at a few points (Moorman et al., 2003; Wollschläger et al., 2010). These difficulties can be overcome by the use of multi-channel systems, which are capable of simultaneously mapping the reflector depth and the average soil water content between surface and reflector (Bradford, 2008; Gerhards et al., 2008). For a permafrost site on the QinghaiTibet Plateau, Wollschläger et al. (2010) demonstrate that the permafrost table and the average soil water content above the frost table can be surveyed with horizontal resolutions of less than one meter, which would be extremely arduous to achieve by a manual method. However, to successfully monitor the seasonal dynamics of the thaw depth, it must be guaranteed that consecutive measurements with multichannel GPR yield consistent results.

In this study, we present a time series of multi-channel GPR measurements of the thaw depth and soil water content at a high-arctic site on Svalbard, Norway, over the course of five weeks. At the chosen study site, rocky soil and thaw depths exceeding $1.5 \mathrm{~m}$ effectively prevent the use of manual probing methods. The study is conducted at the end of the thaw season from mid of August until mid of September, so that the late-summer maximum thaw depth of the active layer can be inferred from the measurements.

\section{Study site}

The study site is located between the glacier Brøggerbreen and the Kongsfjorden at $78^{\circ} 55^{\prime} \mathrm{N}, 11^{\circ} 50^{\prime} \mathrm{E}$, approximately $2 \mathrm{~km} \mathrm{SW}$ of the village of Ny-Ålesund. Due to the influence of the North Atlantic Current, the area features a maritime climate with cool summers and relatively mild winters. The coldest month is February with an average air temperature of around $-14^{\circ} \mathrm{C}$, while the average air temperature is around $+5^{\circ} \mathrm{C}$ during the warmest month July (www.eklima.no, 2010). The annual precipitation is around $400 \mathrm{~mm}$ (Førland et al., 1997), and the snow-free period typically lasts from July to September (Winther et al., 2002).

The radar transects are located in an inactive part of the floodplain of the glacial river Bayelva, which is covered by sparse vegetation, exposed gravel and rock fields (Fig. 1). 
The soil texture ranges from coarse gravel to sand. The site is bordered by the gravel plain of the braided Bayelva River on one side and Leirhaugen hill on the other side. The two radar transects (Fig. 1) are located 200-400 m NW of the Bayelva soil and climate monitoring station on Leirhaugen hill, which has provided a record of soil temperatures in the active layer since 1998 (Roth and Boike, 2001; Boike et al., 2003, 2008). At present, the permafrost at the Bayelva station is relatively warm, with mean annual temperatures around $-2{ }^{\circ} \mathrm{C}$ to $-3^{\circ} \mathrm{C}$ at the bottom of the active layer and a maximum thaw depth of more than $1.5 \mathrm{~m}$.

\section{Methods}

A time series of multi-channel GPR measurements has been recorded along both transects (Fig. 1) during the period between 14 August 2008 and 17 September 2008. The measurements are performed and evaluated using a 4-channel setup as presented in Gerhards et al. (2008). Hence, in the following, only a brief description of the method is summarized together with measurement details which are adapted to the site-specific conditions.

Multi-channel GPR data are acquired by using two shielded $250 \mathrm{MHz}$ RAMAC/GPR antennas in combination with a CUII control unit and an MC-4 multi-channel module (all instruments manufactured by MALÅ Geoscience, Sweden). All radargrams are recorded using a time window of $102 \mathrm{~ns}, 1024$ samples and 4 stacks per trace, and a spatial trace increment of $0.1 \mathrm{~m}$ which is triggered by a survey wheel. All radargrams are processed by employing a dewow filter and by semi-automated picking of reflected wave travel times which are required for the multi-channel evaluation. No amplification is applied to the data sets.

During each survey, both antenna boxes are coupled in a row by a rope with fixed spacings between the boxes. The following factors must be taken into account when determining optimal antenna separations:

- The accuracy and robustness of the method increase, the more the travel times of the channels differ, as the shape of the reflection hyperbola which has to be evaluated during the evaluation procedure (Gerhards et al., 2008) is better defined. With this respect, long separations between the antenna boxes are favorable.

- The amplitude of the GPR signal recorded by the receiving antenna decreases with increasing antenna separation. This is caused by (i) geometrical spreading of the signal and (ii) signal attenuation due to specific ground properties (e.g. electric conductivity). Consequently, the reflected signal eventually fades or at least becomes impossible to pick, if the antenna separation is chosen too long.

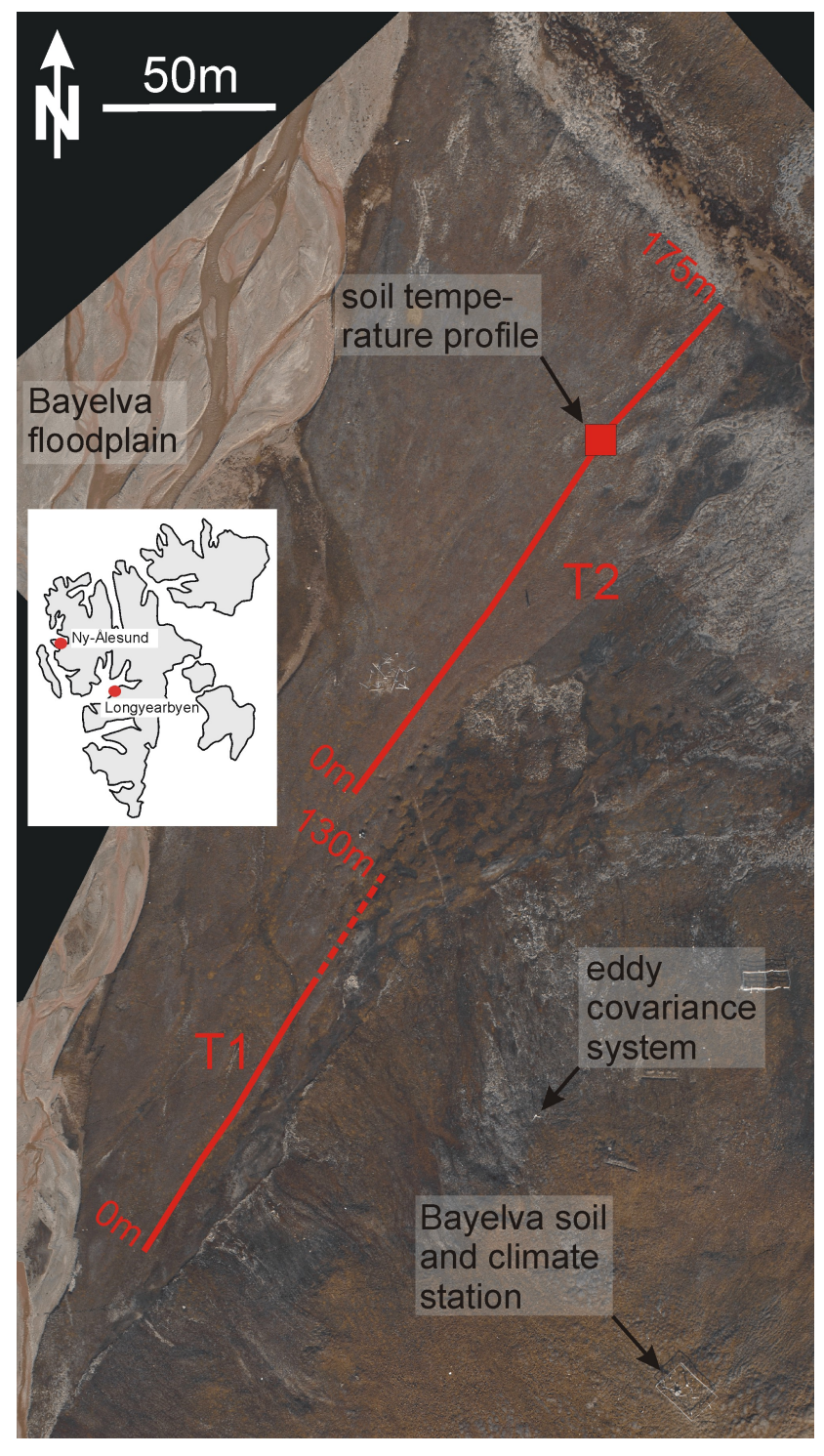

Fig. 1. Orthorectified aerial image of transects $\mathrm{T} 1$ and $\mathrm{T} 2$ (both transects aligned from SW to NE) acquired on 29 August 2008. The dashed part of T1 depicts the section where the radargrams cannot be evaluated (see Fig. 2). The vegetated flat gravel plain, in which the radar transects are located, is bordered by Leirhaugen hill to the $\mathrm{SE}$, on which the eddy covariance system and the Bayelva station are located (elevation difference between the radar transects and the Bayelva station approximately $10 \mathrm{~m}$ ). To the $\mathrm{W}$ of the transects is the floodplain of the Bayelva river, which flows S to N. Transect T2 ends at the banks of a small stream visible in the NE corner. The inset map shows the location of Ny-Ålesund where the study has been performed on Svalbard.

- In addition to the reflected radar signal, a ground wave travels directly through the soil, resulting in an additional signal in the radargrams. If the antenna separations are chosen too long, the ground wave and the 
reflected wave will eventually begin to overlap, resulting in a signal of unclear origin, which is not suitable for picking. Therefore, the antenna separations must be chosen sufficiently short to prevent an overlap between reflected wave and ground wave.

- Choosing a longer antenna separation results in a decrease of the lateral resolution of the evaluation.

The chosen antenna separations (Table 1) represent a compromise for the site-specific conditions in the study area. It allows to pick the reflected wave resulting from the frost table for all four channels, while the ground wave and the reflected wave are clearly separated.

In the multi-channel evaluation for each measurement date, a zero-offset calibration is performed for each individual radargram. For the two (short) box-internal channels, this offset is determined from recorded travel times in air (antenna turned by $90^{\circ}$ ), the transmitter-receiver separation of $0.31 \mathrm{~m}$ and the speed of light. For the long antenna separations, we perform Wide Angle Reflection and Refraction (WARR) measurements in air (antennas turned by $90^{\circ}$ ) in addition to each measured transect, from which the offset is inferred by extrapolating the travel time to zero transmitterreceiver separation. With this, we are able to employ direct measurements of air wave travel times for calibration of each channel and circumvent the indirect airwave adaptation step of Gerhards et al. (2008) during the data evaluation procedure.

The multi-channel evaluation method of Gerhards et al. (2008) assumes that the two-way travel time $t$ of a reflection at a position $x$ in the vicinity of a reference position $x_{0}$ and at antenna separation $a$ is

$t(x ; a)=\frac{\sqrt{\varepsilon_{\mathrm{c}}}}{c_{0}} \cos (\alpha) \sqrt{4\left[d+\left(x_{0}-x\right) \tan (\alpha)\right]^{2}+a^{2}}$

where $\varepsilon_{\mathrm{c}}$ is the soil's bulk relative dielectric permittivity, $c_{0}$ is the speed of light in vacuum $\left(0.3 \mathrm{~m} \mathrm{~ns}^{-1}\right), \alpha$ is the reflector's inclination angle, and $d$ is the reflector depth at $x_{0} . \varepsilon_{\mathrm{c}}, d$ and $\alpha$ are estimated for every position along the radargram using the absolute travel times of the signals measured with all four transmitter-receiver combinations. This is achieved by minimizing the objective function

$\mathrm{OF}(\boldsymbol{b})=\sum_{(n, k)}^{(N, K)}\left(t_{\mathrm{refl}}\left(x_{n}, a_{k}\right)-t_{\text {model }}\left(x_{n}, a_{k} ; \boldsymbol{b}\right)\right)^{2}$

where $\boldsymbol{b}=\left\{\varepsilon_{\mathrm{c}, \mathrm{d}, \alpha}\right\}$ is the parameter vector, $t_{\mathrm{refl}}$ and $t_{\text {model }}$ are the measured and modeled reflected wave travel times for $N$ measurements around $x_{0}$ obtained from $K$ antenna separations, $x_{n}(n=1, \ldots, N)$ are measurement points around $x_{0}$, and $a_{k}(k=1, \ldots, K)$ are the antenna separations. The inversion is conducted with all data available for a pre-defined distance interval around $x_{0}$ which is set to $0.5 \mathrm{~m}$ for this survey.
Table 1. Antenna separations of the four channels used in the radar surveys (determined before and after each survey). Measurement accuracy $5 \mathrm{~mm}$.

\begin{tabular}{crc}
\hline & \multicolumn{2}{c}{ Antenna separations [m] } \\
\cline { 2 - 3 } & \multicolumn{1}{c}{ transect 1} & \multicolumn{1}{c}{ transect 2} \\
\hline $08 / 14 / 2008$ & $2 \times 0.31,1.59,2.21$ & \\
$08 / 15 / 2008$ & & $2 \times 0.31,1.07,1.69$ \\
$08 / 25 / 2008$ & $2 \times 0.31,1.14,1.76$ & $2 \times 0.31,1.15,1.77$ \\
$09 / 02 / 2008$ & $2 \times 0.31,1.07,1.69$ & $2 \times 0.31,1.08,1.70$ \\
$09 / 10 / 2008$ & $2 \times 0.31,1.125,1.745$ & $2 \times 0.31,1.18,1.80$ \\
$09 / 17 / 2008$ & $2 \times 0.31,1.095,1.715$ & $2 \times 0.31,1.08,1.70$ \\
\hline
\end{tabular}

Average volumetric soil water contents of the active layer are calculated from the estimated dielectric permittivities according to Roth et al. (1990) using the CRIM (Complex Refractive Index Model) formula

$\sqrt{\varepsilon_{\mathrm{c}}}=\theta \sqrt{\varepsilon_{\mathrm{w}}}+(1-\phi) \sqrt{\varepsilon_{\mathrm{s}}}+(\phi-\theta) \sqrt{\varepsilon_{\mathrm{a}}}$

where $\phi$ is the porosity, $\theta$ the volumetric soil water content, and $\varepsilon_{\mathrm{c}}$ is composed of the dielectric permittivities of the solid matrix $\left(\varepsilon_{\mathrm{s}}\right)$, water $\left(\varepsilon_{\mathrm{w}}\right)$ and air $\left(\varepsilon_{\mathrm{a}}\right)$, respectively. Rearranging of Eq. (3) and setting $\varepsilon_{\mathrm{a}}=1$ yields

$\theta=\frac{\sqrt{\varepsilon_{\mathrm{c}}}-\sqrt{\varepsilon_{\mathrm{s}}}-\phi\left(1-\sqrt{\varepsilon_{\mathrm{s}}}\right)}{\sqrt{\varepsilon_{\mathrm{W}}}-1}$

for the volumetric soil water content. For the evaluation, the dielectric permittivity of water is set to a constant estimate of $\varepsilon_{\mathrm{W}}=86.1$ which corresponds to a temperature of $5^{\circ} \mathrm{C}$ (Kaatze, 1989). Furthermore, we assume constant values (in space and time) of $\phi=0.4$ and $\varepsilon_{\mathrm{s}}=5$, which are reasonable values for gravel or sand. As the employed values for $\phi$ and $\varepsilon_{\mathrm{S}}$ are not supported by measurements, we assume liberal error margins on both parameters and conduct a thorough error analysis (see Sect. 4.1). We emphasize that the evaluation of the absolute soil water contents using Eq. (4) is only weakly sensitive to the choice of $\phi, \varepsilon_{\mathrm{s}}$ and $\varepsilon_{\mathrm{w}}$ (Roth et al., 1990).

To acquire "ground truth" information on the temperature distribution in the active layer, a profile of four temperature sensors (thermistors and thermocouples) was installed at the 123.6 m-mark of T2 (see Fig. 1). Hereby, the temperature sensors at depths of 1 and $25 \mathrm{~cm}$ below the surface were installed on 23 July 2008, while the deeper sensors at 80 and $150 \mathrm{~cm}$ depth were added on 20 August 2008. During the installation of the deep temperature sensors, the active layer thickness was determined to be $1.55 \mathrm{~m}$ for the location of the temperature profile.

Furthermore, we provide ancillary measurements to assess the water budget of the study site. About 100 to $300 \mathrm{~m}$ from the GPR transects, evapotranspiration was continuously monitored throughout the entire study period in the framework of investigations of the surface energy budget of this 

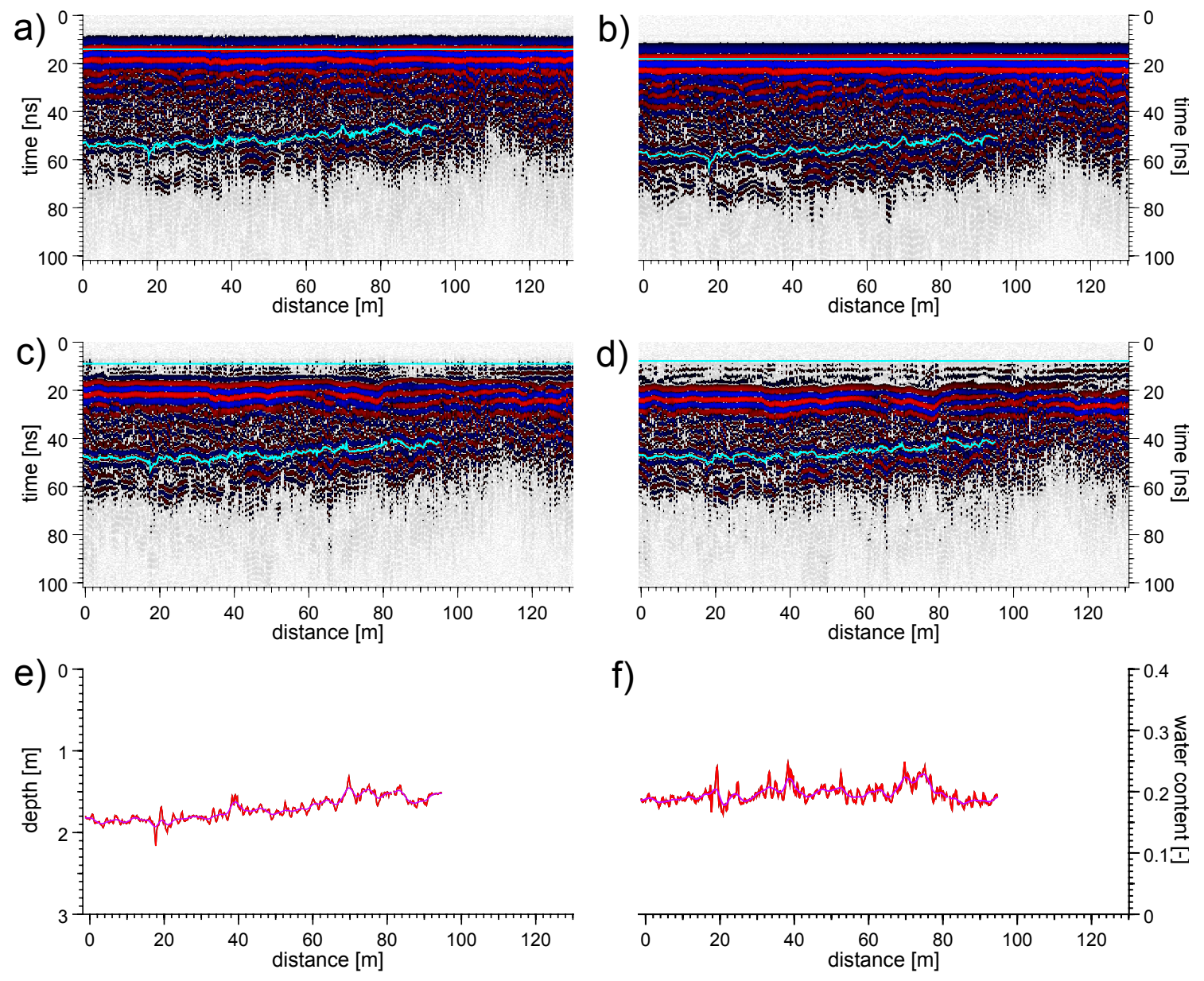

Fig. 2. Transect T1: Radar traces of all four channels and resulting evaluation on 14 August 2008. (a) and (b): antenna separation $0.31 \mathrm{~m}$; (c) $1.59 \mathrm{~m}$; (d) $2.21 \mathrm{~m}$; (e) and (f) resulting thaw depth and volumetric soil water content (red: raw data; purple: smoothed data). It is not possible to evaluate the radargrams beyond about $95 \mathrm{~m}$.

permafrost site (Westermann et al., 2009). For this purpose, an eddy covariance system consisting of a CSAT 3-D sonic anemometer and a LI-7500 $\mathrm{CO}_{2}$ and $\mathrm{H}_{2} \mathrm{O}$ gas analyzer is employed. The evaluation of the raw data is performed with the software package "TK2", in which the commonly used correction and quality test procedures are included (Mauder and Foken, 2004). Details on the eddy covariance measurements and the evaluation procedure are given in Westermann et al. (2009). As both radar transects are not located within the footprint area of the eddy covariance system, the measurements are only used to assess the general magnitude of the evapotranspiration in the area of the radar transects. In addition, we use the daily precipitation record from the Norwegian Meteorological Institute (www.eklima.no, 2010) measured at the village of $\mathrm{Ny}$ Ålesund.

\section{Results}

\subsection{Example radargrams}

Figures 2 and 3 display radargrams of all four channels obtained on 14 and 15 August for the transects T1 and T2. The radargrams feature one dominant reflection caused by the frost table. While this reflection is almost continuous for $\mathrm{T} 2$, the reflection fades after about $95 \mathrm{~m}$ in case of $\mathrm{T} 1$ (see also Fig. 1), so that it is not possible to evaluate the radargrams beyond that point.

The thaw depth decreases by about $30 \mathrm{~cm}$ along the course of $\mathrm{T} 1$, which is of the same order as the variations in thaw depth along T2. The variations in thaw depth are similar to the spatial differences in surface elevation, which are mostly caused by vegetation patches and incised former runoff channels of the Bayelva River (see Fig. 1). Since the surface topography of the transects has not been surveyed, we cannot explore the relation between surface and reflector 
a)
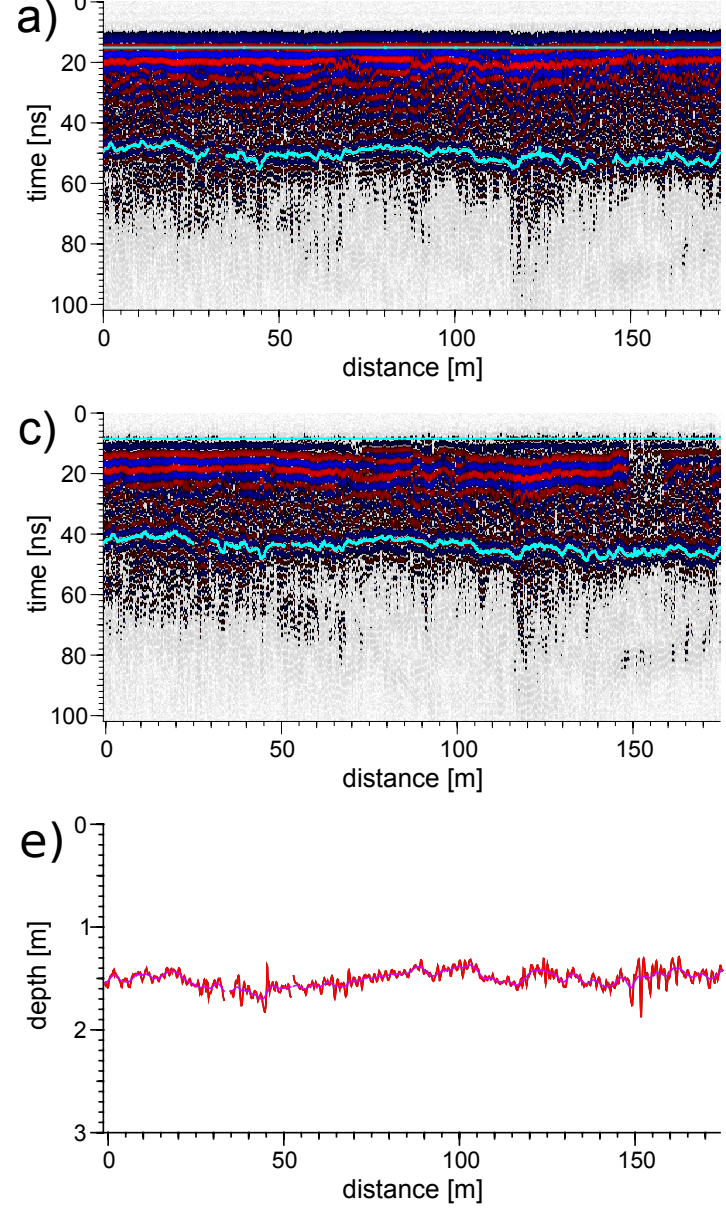

b)
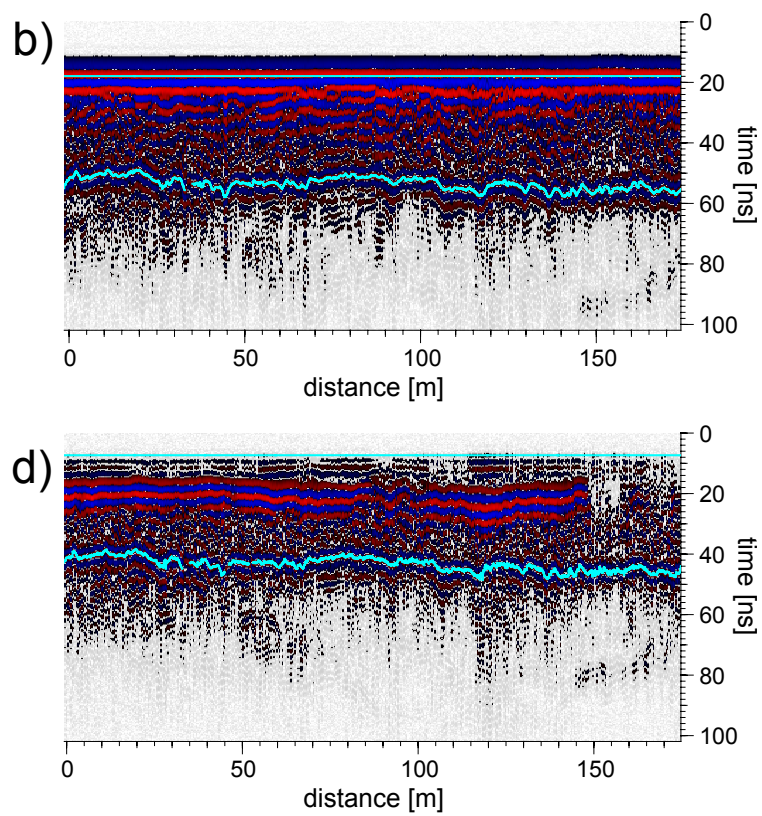

f)

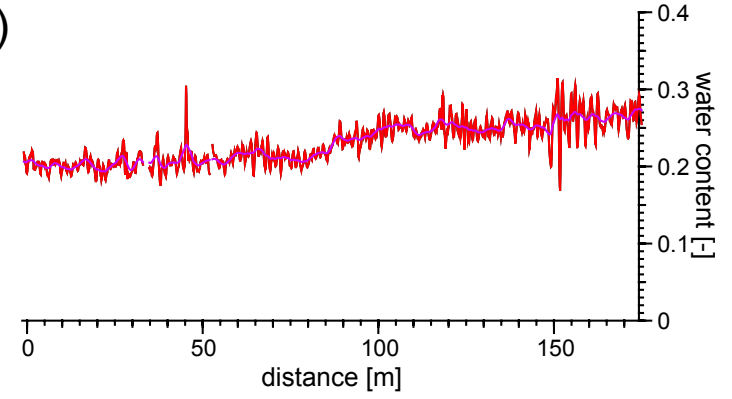

Fig. 3. Transect T2: Radar traces of all four channels and resulting evaluation on 15 August 2008. (a) and (b): antenna separation 0.31 m; (c) $1.07 \mathrm{~m}$; (d) $1.69 \mathrm{~m}$; (e) and (f) resulting thaw depth and volumetric soil water content (red: raw data; purple: smoothed data).

topography. However, given the thaw depths of $1.5 \mathrm{~m}$ and more, the reflector can be characterized as generally flat for both transects. For transect T1, the average soil water content of the thawed zone is rather constant between 0.18 and 0.20 . The slight variations could again be caused by the differences in surface elevation, but they are also in the range of measurement uncertainty (see below). In the course of transect $\mathrm{T} 2$, the soil water content steadily increases from about 0.19 to 0.27 .

For the chosen antenna separations (Table 1), the absolute travel times of the GPR signal do not differ strongly between the four channels (on the order of 5 ns, Figs. 2, 3), which leads to relatively noisy evaluations of reflector topography and soil water content. We therefore apply a spike and a Gaussian filter to the thaw depth and the average soil water content (Figs. 2, 3). This procedure leads to a reduced spatial resolution of our measurements, which seems tolerable for the relatively smooth reflector topography found at the study site.
Two qualitatively different types of uncertainty must be distinguished in the evaluation of thaw depth and average soil water content from the radargrams. Firstly, the zerooffset calibration for the two long antenna separations (using WARR measurements in air, see Sect. 3) is associated with a statistical error, which propagates to thaw depth and soil water content. From repeated WARR measurements in air, we estimate this error to be about 5 to $10 \mathrm{~cm}$ for the thaw depth and about 0.01 to 0.02 for the soil water content. As the zerooffset calibration is different for each survey, these accuracy margins must be taken into account when comparing consecutive radar surveys. However, the error is constant in space, so that the thaw depth and the soil water content would only be shifted for the entire transect.

Furthermore, the assumptions made for the porosity $\phi$ and the dielectric permittivity $\varepsilon_{\mathrm{S}}$ of the solid matrix give rise to an additional uncertainty in the soil water content. If we assume liberal error margins of $\phi=0.4 \pm 0.1$ and $\varepsilon_{\mathrm{s}}=5 \pm 2$, which account for a wide range of soil conditions, the absolute 

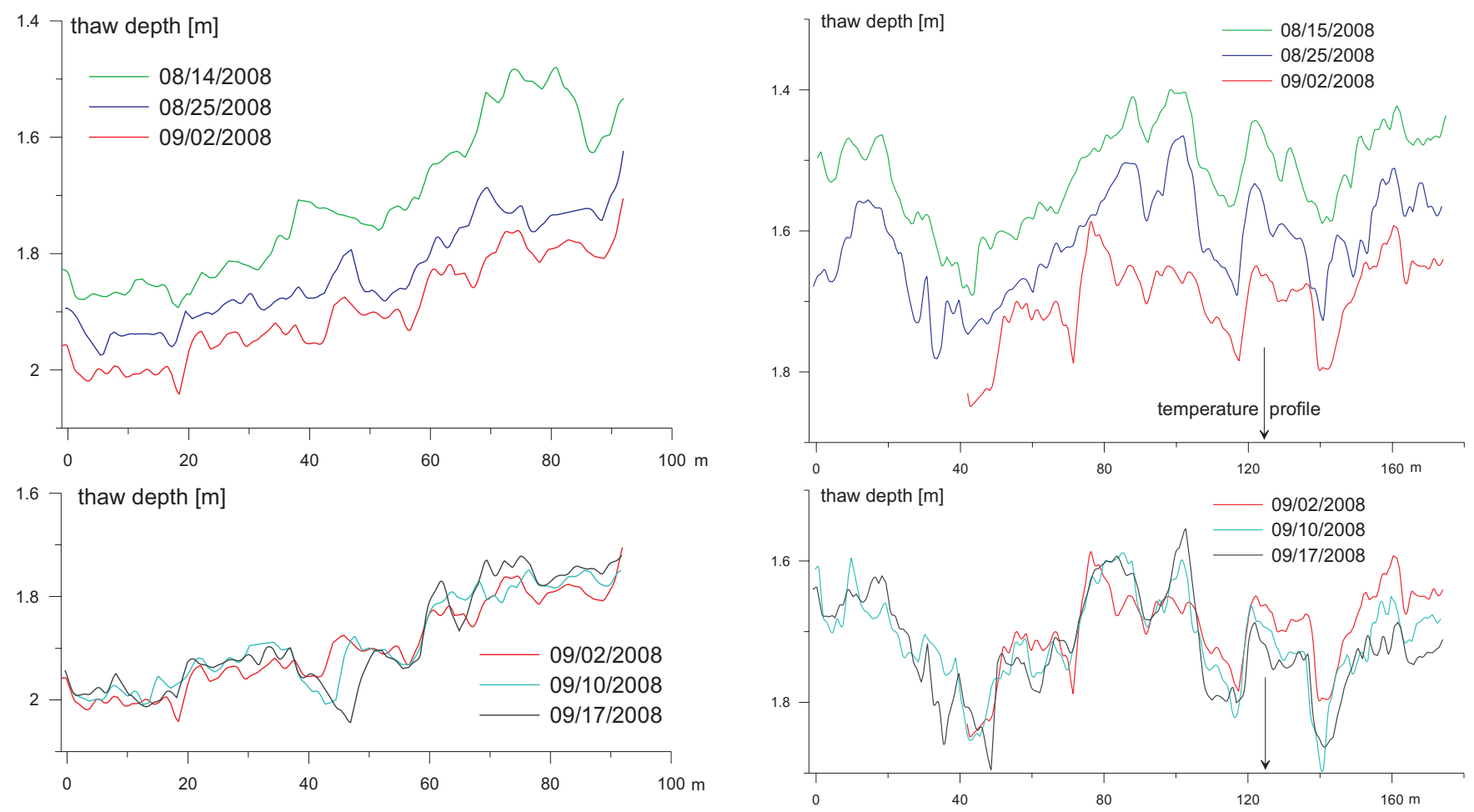

Fig. 4. Transect T1: thaw depth inferred from multi-channel-GPR over a distance of about $95 \mathrm{~m}$.

uncertainty in average soil water content amounts to about 0.03 according to Gaussian error propagation in Eq. 4 (see also Wollschläger et al., 2010). As $\phi$ and $\varepsilon_{\mathrm{S}}$ may change in space, this uncertainty must be considered when comparing soil water contents at different points along the transects. While $\phi$ and $\varepsilon_{\mathrm{S}}$ do not change over time at a specific depth, the depth average may change over time, if layers with different properties thaw and thus contribute to the average values of $\phi$ and $\varepsilon_{\mathrm{s}}$. However, at the recorded thaw depths and rates (see Sect. 4.2), the resulting uncertainty over time is less than 0.01 even for extreme cases (e.g. $\phi=0.3, \varepsilon_{\mathrm{S}}=3$ from 0 to $1.5 \mathrm{~m}, \phi=0.5, \varepsilon_{\mathrm{s}}=7$ from 1.5 to $1.7 \mathrm{~m}$ ). Therefore, we assume $\phi$ and $\varepsilon_{\mathrm{s}}$ to be constant over time in our study, so that the soil water contents determined in consecutive surveys remain unchanged relative to each other at each point.

As the soil temperatures vary in a relatively narrow range (see Sect. 4.3, Fig. 6), the uncertainty due to the temperature dependence of the dielectric permittivity of water, $\varepsilon_{\mathrm{w}}$, is presumed to be negligible in our case.

\subsection{Temporal development of the thaw depth}

The temporal development of the thaw depth for the two transects is displayed in Figs. 4 and 5. Between mid of August and beginning of September, the thaw depths increase by about $20 \mathrm{~cm}$. From beginning to mid of September, the

Fig. 5. Transect T2: thaw depth inferred from multi-channel-GPR over a transect length of about $175 \mathrm{~m}$. For unknown reasons, the survey of transect $\mathrm{T} 2$ conducted on 2 September yields only a weak and discontinuous reflection to about the $40 \mathrm{~m}$ mark, so that it is not possible to infer meaningful thaw depths for this part of the transect. The arrow indicates the position of the instrumented temperature profile (Fig. 6).

thaw depths do not change significantly within the approximate accuracy limit of about 5 to $10 \mathrm{~cm}$ (see Sect. 4.1). The recorded maximum thaw depths range from $1.7 \mathrm{~m}$ to $2.0 \mathrm{~m}$ for $\mathrm{T} 1$ and from $1.6 \mathrm{~m}$ to $1.8 \mathrm{~m}$ for $\mathrm{T} 2$.

In general, the recorded thaw rates observed between mid of August and beginning of September are similar over the course of both transects. Deviations from the average thaw rate are most likely explained by slightly different transect paths used at the different surveys. An example is the part of transect T1 between $65 \mathrm{~m}$ and $85 \mathrm{~m}$ (Fig. 4), where an incised former channel of the Bayelva River (visible in Fig. 1) has been crossed at a different angle on the survey on 14 August compared to the following surveys.

The survey conducted on 2 September of transect T2 yields only a weak and discontinuous reflection from about 0 to $40 \mathrm{~m}$. While the reasons are not clear, we cannot infer meaningful thaw depths (and soil water contents, Fig. 8) for this part of the transect (Fig. 5). 


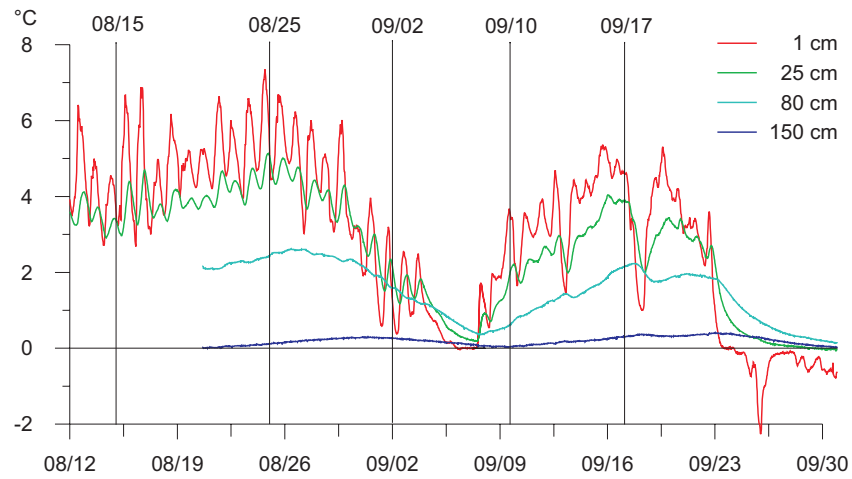

Fig. 6. Temperature profile in the active layer at the position $123.6 \mathrm{~m}$ of transect $\mathrm{T} 2$. The two lower sensors have been added on 20 August 2009. The dates of the radar surveys of transect T2 are indicated as vertical lines.

\subsection{Comparison with ground-truth information on thaw depth}

At $123.6 \mathrm{~m}$ of transect T2, the true thaw depth on 20 August reached $1.55 \mathrm{~m}$, which was determined using a drill. At the same position, the thaw depths inferred from non-invasive multi-channel GPR are about $1.50 \mathrm{~m}$ on 15 August and $1.60 \mathrm{~m}$ on 25 August, which is in good agreement with the thaw depth measured on 20 August.

The hourly soil temperature profile record at $123.6 \mathrm{~m}$ of transect T2 is displayed in Fig. 6. The temperature of the deepest sensor, located at a depth of $1.5 \mathrm{~m}$, increases until beginning of September to a maximum of $+0.3^{\circ} \mathrm{C}$, which is in good agreement with the increase in thaw depth found with GPR. It subsequently decreases towards $0{ }^{\circ} \mathrm{C}$ until approximately 10 September, while temporary refreezing occurs at the surface (Fig. 6). As the "zero curtain", when the soil temperatures within the entire active layer are confined to $0^{\circ} \mathrm{C}$, is not yet reached, the temperature decrease is most likely not associated with detectable refreezing from the bottom. Accordingly, the thaw depths inferred from GPR remain widely unchanged from 2 September to 10 September. Due to an influx of warm air masses in September (Westermann et al., 2009), the soil warms again, so that the warmest temperatures at $1.5 \mathrm{~m}$ depth are reached after mid of September. From the soil temperature data, it is not clear, whether this warming is associated with a further increase in thaw depth. However, it is unlikely that such an increase would have exceeded 5 to $10 \mathrm{~cm}$, so that the GPR measurements, which yield an overall unchanged thaw depth from 10 to 17 September, are in accordance with the temperature profile data within their accuracy limit.

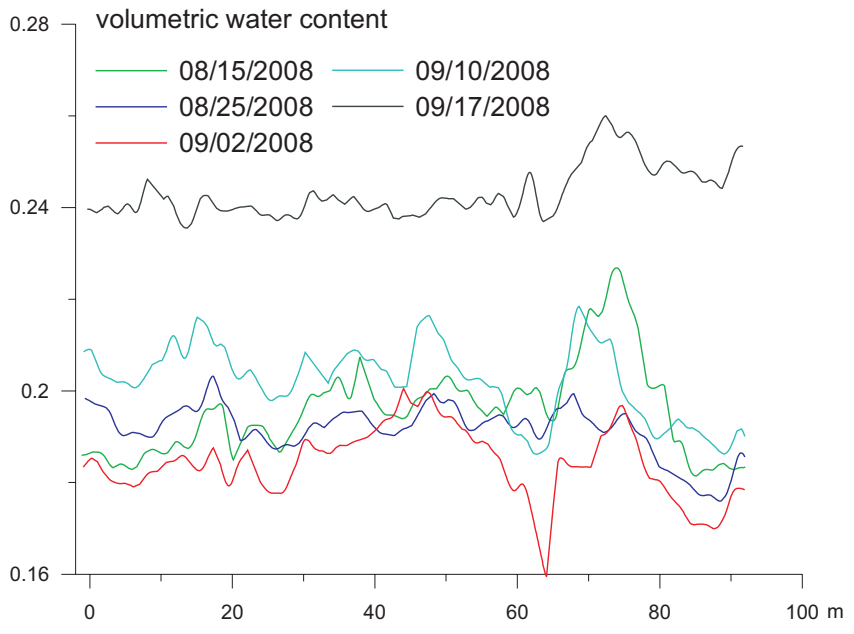

Fig. 7. Transect T1: average volumetric soil water content of the active layer over a distance of $95 \mathrm{~m}$.

\subsection{Soil water content}

Along transect T1, the average volumetric soil water content of the thawed active layer is confined to a range of about 0.18 to 0.21 (Fig. 7). Between about 60 to $80 \mathrm{~m}$, the soil water content features relatively strong variation compared to the other parts of $\mathrm{T} 1$, which could be related to different transect paths across an incised former runoff channel in this part (see Sect. 4.2). Other than that, the soil water content does not change strongly between the first four radar surveys (considering the uncertainty of about 0.01 to 0.02 , see Sect. 4.1), which agrees well with the low evapotranspiration and precipitation rates (Table 2) recorded at this time: as a net water input of $1 \mathrm{~mm}$ would correspond to an increase in average volumetric soil water content of less than 0.001 for thaw depths of more than $1 \mathrm{~m}$, the effect of precipitation and evapotranspiration on the average soil water content can be considered negligible. However, this is certainly not true at the end of the study period. On the final GPR survey, an increase in soil water content to about 0.24 is found (Fig. 7), which is clearly separated from the first four surveys considering the potential uncertainty of about 0.01 to 0.02 . The increase is caused by strong precipitation events between 10 and 17 September with a total water input of approximately $40 \mathrm{~mm}$ (Table 2). At the recorded thaw depths of 1.7 to $2.0 \mathrm{~m}$, this corresponds to an increase in average soil water content of 0.02 to 0.03 , which roughly agrees with the increase of 0.04 inferred from the GPR measurements in the framework of a simplified water budget, where subsurface runoff is not considered.

In the first four surveys of transect $\mathrm{T} 2$, the soil water content increases from 0.18 to 0.20 in the first $50 \mathrm{~m}$ to about 0.28 at the end of the transect (Fig. 8), which is located about $2 \mathrm{~m}$ from the bank of a small stream (visible at the upper 


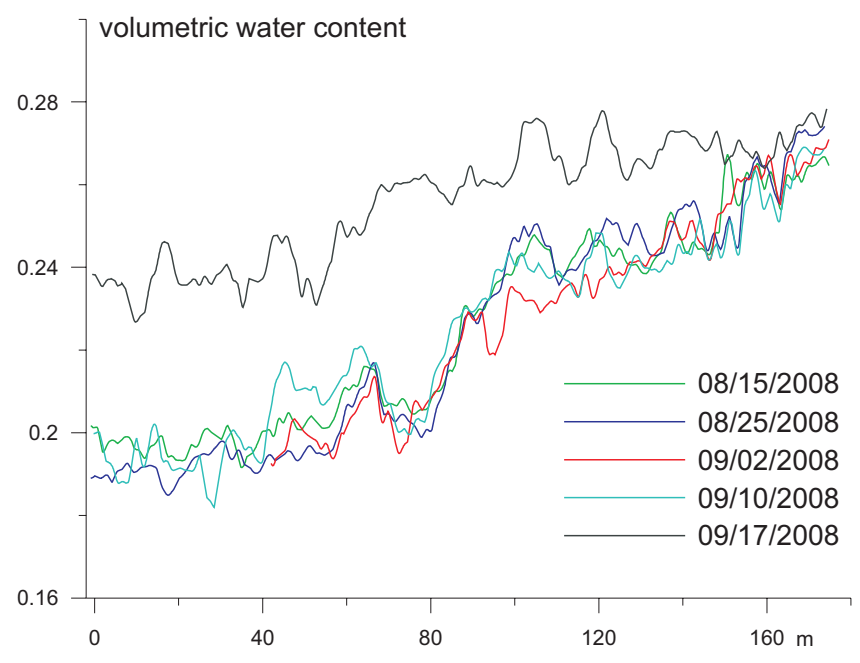

Fig. 8. Transect T2: average volumetric soil water content of the active layer. The radargram obtained on 2 September can not be evaluated between 0 and $40 \mathrm{~m}$ ( refer to Fig. 5).

right corner of Fig. 1). This increase significantly exceeds the uncertainty of the soil water content along the transects, that results from the uncertainty of the employed soil parameters (about 0.03, see Sect. 4.1). During the installation of the soil temperature profile on 20 August at $123.6 \mathrm{~m}$ of T2, the soil was water-saturated below a depth of about $0.5 \mathrm{~m}$, while it was drier above. We therefore hypothesize that a shallow ground water table is located above the frost table in the gravel deposits, so that the soil water content does not vary considerably below a certain level. At the end of the transect, close to the small stream, the ground water table is located closer to the surface corresponding to the higher average soil water content detected by the GPR measurements. Accordingly, the soil water content at the end of the transect is more or less constant after the strong precipitation events at the end of the study period, as most of the soil has already been saturated before due to the proximity of the ground water table to the surface. In contrary, the soil water content in the first $50 \mathrm{~m}$ of the transect increases in a similar way as at transect T1 (Figs. 7, 8). If the interpretation given here is correct, then the saturated conditions at a volumetric soil water content of approximately 0.28 , as found in case of transect T2 (Fig. 8), point to a lower porosity than assumed in the calculation of the soil water content (i.e. $\phi=0.4$ ). We emphasize that the potentially lower porosity has only a small effect on the obtained soil water contents and is explicitly accounted for in our error analysis (see Sect. 3).
Table 2. Total water gain (denoted positive) through precipitation $P$ (measured at the village of Ny-Ålesund, www.eklima.no, 2010 ) and loss through evapotranspiration $E$ (according to eddy covariance measurements performed about $200 \mathrm{~m}$ from the radar transects, Westermann et al., 2009) between consectutive radar surveys. Values rounded to $1 \mathrm{~mm}$. Data on potential subsurface runoff are not available.

\begin{tabular}{rrrr}
\hline & $P[\mathrm{~mm}]$ & $E[\mathrm{~mm}]$ & $P+E[\mathrm{~mm}]$ \\
\hline $08 / 15-08 / 25$ & 3 & -4 & -1 \\
$08 / 25-09 / 02$ & 0 & -2 & -2 \\
$09 / 02-09 / 10$ & 3 & -1 & 2 \\
$09 / 10-09 / 17$ & 38 & -1 & 37 \\
\hline
\end{tabular}

\section{Discussion}

\subsection{Thaw depth and active layer dynamics}

Multi-channel GPR has been capable to deliver the evolution of the thaw depth and the average soil water content between the surface and the freeze-thaw interface for a period of five weeks. For the conditions encountered in the study area (gravelly soil, thaw depths of more than $1.5 \mathrm{~m}$ ), the efficiency of multi-channel GPR must be considered far superior to both manual probing methods and traditional GPR methods such as "Common Mid Point" (CMP) surveys. The accuracy of the obtained thaw depths, which is estimated to be around 5 to $10 \mathrm{~cm}$, is sufficient to secure spatial differences in the thaw depth of about 0.2 to $0.3 \mathrm{~m}$. The main factors limiting the accuracy in the present study are: (1) the zerooffset calibration, and (2) the lack of information on the microtopography. The latter could be accounted for by using automated laser tracking of the radar antennas, as it has been employed by Wollschläger et al. (2010). Despite of such issues, the accuracy of the obtained thaw depths is sufficient to make multi-channel GPR a viable alternative to manual probing in permafrost monitoring. The method would be capable to resolve observed interannual differences of the latesummer thaw depth on the order of $0.3 \mathrm{~m}$ (Christiansen et al., 2010), or decadal trends of the active layer thickness of about 0.2 to $0.4 \mathrm{~m}$ (Åkerman and Johansson, 2008).

At the study area, the thaw depths reach their maximum in the beginning of September and remain approximately constant until at least the mid of the month due to the influx of warm air masses, which again leads to a warming of the upper soil section (Westermann et al., 2009). The maximum thaw depth determined in this study at the end of the summer season corresponds to the thickness of the active layer. The recorded values of $1.6 \mathrm{~m}$ to $2.0 \mathrm{~m}$ are among the highest reported for permafrost on Svalbard so far (Christiansen et al., 2010). For the years 1998 to 2000, Roth and Boike (2001) report an active layer thickness of around $1.0 \mathrm{~m}$ at the Bayelva soil and climate monitoring station (Fig. 1). Since then, the thaw depth at the Bayelva station has increased by more than 
half a meter (Westermann et al., 2009; Boike, 2009), which is in agreement with the increase of permafrost temperatures and active layer thickness found in other regions of Svalbard (Åkerman, 2005; Isaksen et al., 2007). The maximum thaw depth of $2.0 \mathrm{~m}$ found approximately $200 \mathrm{~m}$ from the Bayelva station highlights the possibility that talik formation may commence despite of the northern latitude of the study site, which calls for continued monitoring of permafrost temperatures and active layer thickness. We conclude that a comparable survey of the thaw depths at the study site would not have been possible by manual methods, at least not with a reasonable effort.

While the average soil water contents increase steadily over the course of transect $\mathrm{T} 2$, the thaw depths do not change in a similar way. Likewise, the spatial variations of the thaw depth in transect T1 are not mirrored in the soil water content. This suggests that the thaw depth is not directly related to the average soil water content in the active layer at this permafrost site. Qualitatively, soil moisture has two counterbalancing effects on the thaw depth: while a higher energy input is required to thaw the same soil column in wet compared to dry soil, a higher soil water content also increases the thermal conductivity of the soil and thus facilitates a higher ground heat flux, at least in case of similar temperature gradients. Nevertheless, it is surprising that the net effect of soil moisture on the thaw depth appears to be negligible in our case. A similar example is described by Gerhards et al. (2008), who report almost identical thaw depths in a moist stream bed and in adjacent dry areas at a site on the Qinghai-Tibet Plateau, China.

We cannot readily answer the question what factors cause the variations in thaw depth found at both transects. The surface cover, vegetation and associated albedo do not change strongly over the course of the transects according to a visual inspection. This is confirmed with aerial images obtained on 29 August both with a normal digital camera (Fig. 1) and a near-infrared camera. Furthermore, strong differences in surface soil moisture, which might cause differences in surface temperature (Langer et al., 2010), do not occur in the area of the radar transects. Pronounced differences in the timing of the snow melt can also be excluded: a survey on 30 June revealed rather homogeneous snow depths of around 5 to $10 \mathrm{~cm}$ throughout the study area, while the snow cover had disappeared entirely on 15 July. However, as the spatial differences in the active layer thickness are not drastic regarding the absolute value of up to $2 \mathrm{~m}$, it seems possible that variations of the soil properties, e.g. caused by a different sand to gravel ratio, can sufficiently explain the variations of the thaw depth.

\subsection{Latent heat content of the active layer}

From thaw depth and average soil water content of the active layer, the total content of latent heat (due to unfrozen water) of the active layer can be calculated, which is a coarse ap- proximation for the total energy content of the ground. The advantage of multi-channel GPR is that it inherently delivers depth averages of the soil water content, which can otherwise only be derived from a number of invasive "point"-like measurements, e.g. by using gravimetric methods or TimeDomain-Reflectometry (TDR). The latent heat content stored in the active layer is a coarse estimate for the energy which has to be released during winter for a complete refreezing of the active layer. If this energy is not released during the winter season, the soil temperatures within the active layer remain close to $0^{\circ} \mathrm{C}$ or at least within the freezing range of the soil, which may be a trigger for initial talik formation. In 2008, the increase in average soil water content detected on the last survey on 17 September, occurs just before the refreezing of the soil. This increase in latent heat content, that is caused by strong precipitation events (Table 2), presumably leads to a delayed refreezing of the active layer. At the study site, this may be of particular importance, as in many years an insulating snow pack forms early during winter (Roth and Boike, 2001; Westermann et al., 2009), which effectively limits the release of energy from the soil. Therefore, the occurrence of strong precipitation during fall may be a contributing factor for the formation of taliks, especially in combination with a warm winter and/or a high and early snow cover.

The real energy, that has to be released for the refreezing of the active layer, is higher than the latent heat content determined with GPR, as there is also a contribution of sensible heat due to the cooling of the soil. Furthermore, there may be unfrozen water below the active layer at subzero temperatures, which increases the total latent heat content. Nevertheless, the latent heat content of the active layer inferred from GPR measurements constitutes a lower bound for the energy that must be released during winter. Therefore, multichannel GPR measurements performed directly before the refreezing of the active layer can contribute to locating potential "weak spots" in permafrost areas, where talik formation and thus initial permafrost degradation may commence, and may thus serve as a tool to assess the vulnerability of permafrost.

\subsection{Inferring ground heat fluxes from multi-channel ground-penetrating radar?}

From consecutive multi-channel GPR measurements, the change in latent heat content of the active layer can be evaluated, if evapotranspiration, precipitation and/or subsurface runoff do not considerably change the average soil water content. As presented in Sect. 4.4, this is the case at least for evapotranspiration and precipitation for the time between mid of August and beginning of September. The change $\Delta E$ in latent heat content per unit area between times $t_{1}$ and $t_{2}$ with thaw depth $d(t)$ 
and average volumetric soil water content $\theta(t)$ is given as

$\Delta E=L\left[d\left(t_{2}\right) \theta\left(t_{2}\right)-d\left(t_{1}\right) \theta\left(t_{1}\right)\right]$

where $L=334 \mathrm{MJ} \mathrm{m}^{-3}$ denotes the latent heat of fusion of water. For the radar transects, the thaw depth increases by about $0.2 \mathrm{~m}$ between 15 August and 2 September, while the average volumetric soil water content remains approximately constant in time and varies from 0.2 to 0.27 along the transects. This results in an energy gain of 13 to $18 \mathrm{MJ} \mathrm{m}^{-2}$ or an average heat flux of 8 to $11 \mathrm{~W} \mathrm{~m}^{-2}$. As it is not possible to evaluate the sensible heat content of the soil from the GPR measurements, we use the instrumented temperature profile (Fig. 6) to estimate the average temperature change of the soil column. From 15 August to 2 September, the uppermost $1.5 \mathrm{~m}$ on average cool by about 0.5 to $1.0 \mathrm{~K}$ (estimate from Fig. 6). This corresponds to a decrease in sensible heat content of approximately 1.5 to $4.0 \mathrm{MJ} \mathrm{m}^{-2}$ for an estimated specific heat capacity of 2.0 to $2.5 \mathrm{MJ} \mathrm{m}^{-3} \mathrm{~K}^{-1}$ (Westermann et al., 2009), or an average heat flux due to the change of the sensible heat content of -1.0 to $-2.5 \mathrm{~W} \mathrm{~m}^{-2}$. Thus, we obtain average ground heat fluxes in the range between 5.5 and $10.0 \mathrm{~W} \mathrm{~m}^{-2}$ as a coarse estimate for the study area. The data set presented in Westermann et al. (2009), for which the ground heat flux is evaluated at a site located 100 to $400 \mathrm{~m}$ from the radar transects in more fine-grained soil, shows an average ground heat flux of 4.5 to $6.5 \mathrm{~W} \mathrm{~m}^{-2}$ for the same time period. Although some differences may exist between the ground heat fluxes at the two sites, the rough agreement suggests that the general magnitude of the average ground heat flux can indeed be estimated from multi-channel GPR if additional measurements of soil temperatures are available for some points. Furthermore, the spatially resolved information on ground heat fluxes provided by multi-channel GPR can help to assess the representativeness of commonly employed point measurements for a certain area, e.g. the footprint area of an eddy covariance system.

The presented method does not account for changing temperatures below the freezing front, which give rise to additional terms of sensible and latent heat (through changes in unfrozen water content at subzero temperatures), so that the ground heat fluxes inferred from multi-channel GPR may in some cases be biased. As the unfrozen water content at subzero temperatures is particularly high for fine-grained soils, the method may not be applicable in such soils. For the gravelly and sandy soils at our study site, we do not expect a major bias of our flux estimates.

The estimation of the sensible heat content of the soil could be improved by measuring time series of the surface temperature at a few representative points along the radar transects, from which one can numerically evaluate the full temperature distribution between the ground surface and the freeze-thaw interface (e.g. Romanovsky and Osterkamp, 1997; Westermann et al., 2009). We emphasize that such a scheme would rely entirely on non-invasive techniques. Given the major problems and accuracy issues asso- ciated with all presently employed methods for determining the ground heat flux, it is desirable to further evaluate the prospects of multi-channel GPR for determining ground heat fluxes in permafrost areas.

\section{Summary and conclusion}

In this study, we investigate the active layer dynamics at a permafrost site on Svalbard using multi-channel groundpenetrating radar. The results demonstrate that multi-channel GPR measurements

- are a non-invasive technique to determine the active layer thickness, even if it exceeds $1.5 \mathrm{~m}$ (given an analyzable reflection),

- are capable of reproducing the seasonal evolution of the thaw depth within an accuracy of 5 to $10 \mathrm{~cm}$,

- can map and monitor changes in the average soil water content of the active layer, which is otherwise not accessible using non-invasive techniques,

- can be used to spatially map the latent heat content of the active layer,

- hold potential to spatially map weekly to monthly averages of the ground heat flux, which is of great interest for a better understanding of the energy budget in permafrost areas.

Acknowledgements. We are grateful to K. Roth for the advice and for providing us with the radar equipment. We thank K. Piel for valuable support during the field work and M. Langer and J. Buchner for thoughtful comments and suggestions. H. Juliussen and J. Moore provided constructive criticism and valuable suggestions in the review process, which helped to improve the manuscript. We thank M. Schumacher, E. Larmanou, M. Sieber and A. le Tressoler from the AWIPEV base in Ny-Ålesund for the ongoing support of our permafrost research, which contributed greatly to the success of this work. We gratefully acknowledge financial support by the Helmholtz Association through a grant (VH-NG 203) awarded to Julia Boike.

Edited by: S. Gruber

\section{References}

Åkerman, H.: Relations between slow slope processes and activelayer thickness 1972-2002, Kapp Linné, Svalbard, Norsk Geogr. Tidsskr., 59, 116-128, 2005.

Åkerman, H. and Johansson, M.: Thawing permafrost and thicker active layers in sub-arctic Sweden, Permafrost Periglac., 19, 279-292, 2008.

Annan, A. and Davis, J.: Impulse radar sounding in permafrost, Radio Sci., 11, 383-394, 1976. 
Arcone, S., Lawson, D., Delaney, A., Strasser, J., and Strasser, J.: Ground-penetrating radar reflection profiling of groundwater and bedrock in an area of discontinuous permafrost, Geophysics, 63, 1573, doi:10.1190/1.1444454, 1998.

Boike, J.: SPARC and disappearing permafrost - a story from Bayelva in Svalbard, Svalbard Science Forum, http://ssf.npolar. no/pages/news318.htm, 2009.

Boike, J., Roth, K., and Ippisch, O.: Seasonal snow cover on frozen ground: Energy balance calculations of a permafrost site near Ny-Ålesund, Spitsbergen, J. Geophys. Res.-Atmos., 108, 81638173, 2003.

Boike, J., Ippisch, O., Overduin, P., Hagedorn, B., and Roth, K.: Water, heat and solute dynamics of a mud boil, Spitsbergen, Geomorphology, 95, 61-73, 2008.

Bradford, J.: Measuring water content heterogeneity using multifold GPR with reflection tomography, Vadose Zone J., 7, 184, 184-193, 2008.

Bradford, J., McNamara, J., Bowden, W., and Gooseff, M.: Measuring thaw depth beneath peat-lined arctic streams using groundpenetrating radar, Hydrol. Process., 19, 2689-2699, 2005.

Brosten, T., Bradford, J., McNamara, J., Zarnetske, J., Gooseff, M., and Bowden, W.: Profiles of temporal thaw depths beneath two arctic stream types using ground-penetrating radar, Permafrost Periglac., 17, 341-355, 2006.

Brown, J., Ferrians Jr., O., Heginbottom, J., and Melnikov, E.: Circum-Arctic map of permafrost and ground-ice conditions, US Geological Survey Circum-Pacific Map, 1997.

Brown, J., Hinkel, K., and Nelson, F.: The circumpolar active layer monitoring (CALM) program: research designs and initial results, Polar Geography, 24, 166-258, 2000.

Christiansen, $\mathrm{H}$. and Humlum, O.: Interannual variations in active layer thickness in Svalbard, in: Proceedings of the Ninth International Conference on Permafrost, edited by: Kane, D. L. and Hinkel, K. M., Fairbanks, Alaska., Vol. 1, 257-262, 2008.

Christiansen, H., Etzelmüller, B., Isaksen, K., Juliussen, H., Farbrot, H., Humlum, O., Johansson, M., Ingeman-Nielsen, T., Kristensen, L., Hjort, J. J., Holmlund, P., Sannel, A., Sigsgaard, C., Åkerman, H., Foged, N., Blikra, L., Pernosky, M., and Ødegård, R.: The thermal state of permafrost in the nordic area during the international polar year 2007-2009, Permafrost Periglac., 21, 156-181, 2010.

Comiso, J. and Parkinson, C.: Satellite-observed changes in the Arctic, Phys. Today, 57, 38-44, 2004.

Davis, J. and Annan, A.: Ground-penetrating radar for highresolution mapping of soil and rock stratigraphy, Geophys. Prospect., 37, 531-551, 1989.

Delisle, G.: Near-surface permafrost degradation: How severe during the 21st century?, Geophys. Res. Lett., 34, 9503, doi: 10.1029/2007GL029323, 2007.

Førland, E., Hanssen-Bauer, I., and Nordli, P.: Climate statistics and longterm series of temperatures and precipitation at Svalbard and Jan Mayen, Det Norske Meteorologiske Institutt Klima Report 21/97, 1997.

Gerhards, H., Wollschläger, U., Yu, Q., Schiwek, P., Pan, X., and Roth, K.: Continuous and simultaneous measurement of reflector depth and average soil-water content with multichannel ground-penetrating radar, Geophysics, 73, J15-J23, doi: 10.1190/1.2943669, 2008.

Harris, S., French, H., Heginbottom, J., Johnston, G., Ladanyi, B.,
Sego, D., and van Everdingen, R.: Glossary of permafrost and related ground ice terms, Permafrost Subcommittee, Associate Committee on Geotechnical Research, National Research Council of Canada, Ottawa, 1988.

Hinkel, K. and Nelson, F.: Spatial and temporal patterns of active layer thickness at Circumpolar Active Layer Monitoring (CALM) sites in northern Alaska, 1995-2000, J. Geophys. Res., 108, 8168, doi:10.1029/2001JD000927, 2003.

Hinkel, K., Doolittle, J., Bockheim, J., Nelson, F., Paetzold, R., Kimble, J., and Travis, R.: Detection of subsurface permafrost features with ground-penetrating radar, Barrow, Alaska, Permafrost Periglac., 12, 179-190, 2001.

Hinzman, L., Bettez, N., Bolton, W., Chapin, F., Dyurgerov, M., Fastie, C., Griffith, B., Hollister, R., Hope, A., Huntington, H., Jensen, A., Jia, G., Jorgenson, T., Kane, D., Klein, D., Kofinas, G., Lynch, A., Lloyd, A., McGuire, A., Nelson, F., Oechel, W., Osterkamp, T., Racine, C., Romanovsky, V., Stone, R., Stow, D., Sturm, M., Tweedie, C., Vourlitis, G., Walker, M., Walker, D., Webber, P., Welker, J., Winker, K., and Yoshikawa, K.: Evidence and implications of recent climate change in northern Alaska and other arctic regions, Climatic Change, 72, 251-298, 2005.

Isaksen, K., Sollid, J., Holmlund, P., and Harris, C.: Recent warming of mountain permafrost in Svalbard and Scandinavia, J. Geophys. Res.-Earth, 112, F02S04, doi:10.1029/2006JF000522, 2007.

Jorgenson, M., Racine, C., Walters, J., and Osterkamp, T.: Permafrost degradation and ecological changes associated with a warming climate in Central Alaska, Climatic Change, 48, 551579, 2001.

Kaatze, U.: Complex permittivity of water as a function of frequency and temperature, J. Chem. Eng. Data, 34, 371-374, 1989.

Langer, M., Westermann, S., and Boike, J.: Spatial and temporal variations of summer surface temperatures of wet polygonal tundra in Siberia - implications for MODIS LST based permafrost monitoring, Remote Sens. Environ. 114(9), 2059-2069, 2010.

Lawrence, D., Slater, A., Romanovsky, V., and Nicolsky, D.: Sensitivity of a model projection of near-surface permafrost degradation to soil column depth and representation of soil organic matter, J. Geophys. Res., 113, F02011, doi:10.1029/2007JF000883, 2008.

Mauder, M. and Foken, T.: Documentation and instruction manual of the eddy covariance software package TK2, Univ. of Bayreuth, Dept. of Mikrometeorology, 2004.

Moorman, B., Robinson, S., and Burgess, M.: Imaging periglacial conditions with ground-penetrating radar, Permafrost Periglac., 14, 319-329, 2003.

Nelson, F., Shiklomanov, N., Hinkel, K., and Brown, J.: Decadal results from the Circumpolar Active Layer Monitoring (CALM) Program, in: Proceedings of the Ninth International Conference on Permafrost, edited by: Kane, D. L. and Hinkel, K. M., Fairbanks, Alaska., Vol. 2, 1273-1280, 2008.

Oelke, C., Zhang, T., and Serreze, M.: Modeling evidence for recent warming of the Arctic soil thermal regime, Geophys. Res. Lett., 31, L07208, doi:10.1029/2003GL019300, 2004.

Osterkamp, T.: The recent warming of permafrost in Alaska, Global Planet. Change, 49, 187-202, 2005.

Osterkamp, T.: Characteristics of the recent warming of permafrost in Alaska, J. Geophys. Res.-Earth, 112, F02S02, doi:10.1029/ 2006JF000578, 2007. 
Overland, J., Wang, M., and Salo, S.: The recent Arctic warm period, Tellus A, 60, 589-597, 2008.

Parker, W.: Effect of permafrost changes on economic development, environmental security and natural resource potential in Alaska, in: Permafrost response on economic development, environmental security and natural resources, Kluver Academic Publishers, Dordrecht, The Netherlands, 293-296, 2001.

Prowse, T., Furgal, C., Chouinard, R., Melling, H., Milburn, D., and Smith, S.: Implications of climate change for economic development in Northern Canada: energy, resource, and transportation sectors, AMBIO: A Journal of the Human Environment, 38, 272-281, 2009.

Romanovsky, V. and Osterkamp, T.: Thawing of the active layer on the coastal plain of the Alaskan Arctic, Permafrost Periglac., 8, 1-22, 1997.

Roth, K. and Boike, J.: Quantifying the thermal dynamics of a permafrost site near Ny-Ålesund, Svalbard, Water Resour. Res., 37, 2901-2914, 2001.

Roth, K., Schulin, R., Flühler, H., and Attinger, W.: Calibration of time domain reflectometry for water content measurement using a composite dielectric approach, Water Resour. Res., 26, 22672273, 1990.

Schuur, E., Bockheim, J., Canadell, J., Euskirchen, E., Field, C., Goryachkin, S., Hagemann, S., Kuhry, P., Lafleur, P., Lee, H., Mazhitova, G., Nelson, F., Rinke, A., Romanovsky, V., Shiklomanov, N., Tarnocai, C., Venevsky, S., Vogel, J., and Zimov, S.: Vulnerability of permafrost carbon to climate change: Implications for the global carbon cycle, Bioscience, 58, 701-714, 2008.

Schwamborn, G., Wagner, D., and Hubberten, H.: The use of GPR to detect active layer in young periglacial terrain of Livingston Island, Maritime Antarctica, Near Surf. Geophys., 6, 327-332, 2008.

Serreze, M., Walsh, J., Chapin, F., Osterkamp, T., Dyurgerov, M., Romanovsky, V., Oechel, W., Morison, J., Zhang, T., and Barry, R.: Observational evidence of recent change in the northern highlatitude environment, Climatic Change, 46, 159-207, 2000.
Shiklomanov, N., Nelson, F., Streletskiy, D., Hinkel, K., and Brown, J.: The Circumpolar Active Layer Monitoring (CALM) program: Data collection, management, and dissemination strategies, in: Proceedings of the Ninth International Conference on Permafrost, edited by: Kane, D. L. and Hinkel, K. M., Fairbanks, Alaska, Vol. 2, 1647-1652, 2008.

Westermann, S., Lüers, J., Langer, M., Piel, K., and Boike, J.: The annual surface energy budget of a high-arctic permafrost site on Svalbard, Norway, The Cryosphere, 3, 245-263, doi:10.5194/tc3-245-2009, 2009.

Winther, J., Godtliebsen, F., Gerland, S., and Isachsen, P.: Surface albedo in Ny-Ålesund, Svalbard: variability and trends during 1981-1997, Global Planet. Change, 32, 127-139, 2002.

Wollschläger, U., Gerhards, H., Yu, Q., and Roth, K.: Multi-channel ground-penetrating radar to explore spatial variations in thaw depth and moisture content in the active layer of a permafrost site, The Cryosphere, 4, 269-283, doi:10.5194/tc-4-269-2010, 2010.

www.eklima.no: Free access to weather- and climate data from Norwegian Meteorological Institute from historical data to real time observations, http://www.eklima.no, 2010.

Zhang, T., Frauenfeld, O., Serreze, M., Etringer, A., Oelke, C., McCreight, J., Barry, R., Gilichinsky, D., Yang, D., Ye, H., Ling, F., and Chudinova, S.: Spatial and temporal variability in active layer thickness over the Russian Arctic drainage basin, J. Geophys. Res.-Atmos., 110, D16101, doi:10.1029/2004JD005642, 2005.

Zimov, S., Schuur, E., and Chapin III, F.: Permafrost and the global carbon budget, Science, 312, 1612-1613, 2006. 